\title{
Study of on-line Monitoring of XLPE Cable's Device and Assessment by Fuzzy Theory
}

\author{
Juwei Ye $\mathrm{e}^{1, \mathrm{a}}$, Qinghuan Qin ${ }^{1, \mathrm{a}}$, Chen Luo ${ }^{2, \mathrm{~b}}$, Shufang $\mathrm{Li}^{1, \mathrm{a}}$, Kai Su${ }^{1, \text { a }}$, Yineng \\ $\mathrm{BaO}^{1, \mathrm{a}}$ and Zhanglong Zhang ${ }^{2, \mathrm{~b}}$ \\ ${ }^{1}$ Electric power supply company of Songyang, Zhejiang, 323400, China
}

${ }^{2}$ State Key Laboratory of Power Transmission Equipment \& System Security and New Technology, Chongqing University, Chongqing, 400044 , China

\begin{abstract}
Keywords: XLPE cableInsulation assessment, On-line monitoring, Fuzzy theory
Abstract. With the increase of XLPE cable we used in power network, the corresponding technology of on-line monitoring becomes increasingly important. For improving the accuracy of on-line monitoring assessment of XLPE cable, we researched an assessment method and device of XLPE cable's insulation state by Fuzzy Theory. According to legitimately distribute between Fuzzy set and membership function in Fuzzy Theory, we solved the problem that how to distribute the membership of XLPE cable's insulation parameters and accomplished the assessment of XPLE cable's insulation state. The experimental operation results showed that the device can operate stably and interactwith background monitoring platform in real-time, which accomplished the on-line monitoring of XLPE cable and assessment of its insulation state. It can effectively ensure the safety of power network's operation.
\end{abstract}

\section{Introduction}

The XLPE cable have widely been used because it has many advantages that excellent electrical performance, lightweight structure, simple process, convenient laying and so on. With the increase of XLPE stable's usage amount from year to year, the corresponding task of assessment insulation becomes increasingly important. For ensuring the safety of cable operation, the latest on-line monitoring technology has been designed in China and abroad, which include DC superposition method, Dielectric loss factor method, DC component method, Grounding current method, Partial discharge method, Temperature monitoring method and so on. However, on the one hand, because there is not a structure criterion of on-line monitoring of XLPE cable, and the devices are subject to interfe, rence in the field. On the other hand, the method has some defects and the limitation of the precision of monitoring device. These factors cause that it can't assess the insulation state of cable accurately by single method. So the method of appraisal and diagnosis is subject to uncertainty.

Based on above consideration, this paper puts forward an on-line monitoring of XLPE cable's device and assessment by Fuzzy Theory. It solves the credence assignment problem of XLPE cable's insulation parameter and accomplish the assessment of XLPE cable insulation state. The experimental operation results showed that, the device can collect and transport the data of cable in effect and keep to interact with background monitoring platform in real-time, which accomplished the on-line monitoring of XLPE cable and assessment of its insulation state. It proves the safety of the power network operation and increase the engineering working efficiency in effect.

\section{The assessment method by Fuzzy Theory}

The Fuzzy Theory, a method of diagnosing malfunction, is based on the fuzzy set and the membership function, which is used to find the fuzzy relation between malfunction cause and indication when diagnosing malfunction. The degree of membership show the uncertainty of malfunction, which means the probability of causing malfunction.

\subsection{The construction of evaluation factor set}

Assessing the insulation state of XLPE cable by Fuzzy Theory, firstly, we should determine the parameter features of monitoring we need. The definition and collection of parameter features are the basement of on-line monitoring and assessing insulation state of electrical cable. There are 
many kinds of parameter features that include itself features and the features of surrounding environment. The paper expounds that how to accomplish the assessment of XLPE cable's insulation state by Fuzzy Theory. The corresponding features are effective value of grounding capacitance current, the current of peak pulse, the frequency of pulse current, the temperature of cable joint surface and the environmental relative humidity.

Usingthe chosen features, the established features set is $U=\{u 1, u 2, u 3, u 4, u 5\}=\{$ effective value of grounding capacitance current, the current of peak pulse, the frequency of pulse current, the temperature of cable joint surface and the environmental relative humidity\}; The Fi expresses effective value of grounding capacitance current, the Fp expressesthe current of peak pulse, the Ff expresses the frequency of pulse current, the $T$ expresses the temperature of cable joint surface and the $\mathrm{H}$ expresses the environmental relative humidity. The environmental relative humidity don't directly show the insulationstate of cable but affect the value of cable's leakage current. The leakage current of cable is an important parameter of cable's insulation. And there is different leakage current state with different the environmental relative humidity. So the insulation state is relatively showed by the environmental relative humidity. But the current of peak pulse has a relation with the frequency of pulse current, so the U2 and U3 are united asa factor U12. Above all, we establish an evaluationfactor set that is $\mathrm{U}=\left\{u_{1}, u_{12}, u_{4}, u_{5}\right\}$.

\subsection{Determine the weight of evaluation factor}

1) Establish the fuzzy reciprocal matrix

Suppose the matrix $A=($ aij $) n \times n$, if $A$ conforms to aij+aji $=1(i, j=1,2, \ldots, n)$, the matrix $A$ is defined as fuzzy reciprocal matrix. In FAHP, the evaluation factors are compared with each other to get the fuzzy reciprocal matrix A. By comparing the insulation parameter each other for importance of insulation level, we can get:

$$
\mathrm{A}=\left[\begin{array}{llll}
a_{11} & a_{12} & \ldots & a_{1 n} \\
a_{21} & a_{22} & \ldots & a_{2 n} \\
\cdots & \ldots & \ldots & \ldots \\
a_{n 1} & a_{n 2} & a_{n 3} & a_{n n}
\end{array}\right] .
$$

Among, the aij expresses the evaluating factor of degree that ai is more important than aj. As shown above, the current of peak pulse has a relation with the frequency of pulse current, so the U2 and $\mathrm{U} 3$ are united as a factor U12. By referring parameter standard of cable, we can get:

$$
\mathrm{A}=\left[\begin{array}{cccc}
0.5 & 0.6 & 0.85 & 0.95 \\
0.4 & 0.5 & 0.75 & 0.85 \\
0.15 & 0.25 & 0.5 & 0.6 \\
0.05 & 0.15 & 0.4 & 0.5
\end{array}\right]
$$

2) Solve consistent matrix

People consistency of judgement thinking is reflected byconsistency of fuzzy reciprocal matrix. However, in researching on practical problem, due to the partial understanding of people concept and the problem complexity, the fuzzy reciprocal matrix we construct is inconsistent, which is adjusted to the fuzzy consistent matrix.

Suppose the consistent matrix:

$$
\mathrm{B}=\left(\mathrm{b}_{\mathrm{ij}}\right) \mathrm{n} \times \mathrm{n}, \quad b_{i}=\sum_{k=1}^{n} a_{i k} ; \mathrm{b}_{\mathrm{ij}}=\left(\mathrm{b}_{\mathrm{i}}-\mathrm{b}_{\mathrm{j}}\right) /[2(\mathrm{n}-1)]+0.5 .
$$

The matrix A is substituted into formula (3) for calculating consistent matrix: 


$$
\mathrm{B}=\left[\begin{array}{cccc}
0.5 & 0.567 & 0.733 & 0.8 \\
0.433 & 0.5 & 0.667 & 0.733 \\
0.267 & 0.333 & 0.5 & 0.567 \\
0.2 & 0.267 & 0.433 & 0.5
\end{array}\right]
$$

Suppose the weight of evaluation factors $\mathrm{u} 1, \mathrm{u} 2, \ldots$, un are $\mathrm{w}_{1}, \mathrm{w}_{2}, \ldots, \mathrm{w}_{\mathrm{n}}$. And then, by relational backward elimination method, we calculate the evaluation factors:

$$
w_{i}=\frac{1}{n}-\frac{1}{2 \alpha}+\frac{1}{n \alpha} \sum_{k=1}^{n} b_{i k} \quad \mathrm{i} \in\{1.2 \ldots \ldots \mathrm{n}\}
$$

In formula, $\alpha=(n-1) / 2$ is an adjusted parameter. The parameter of matrix $B$ is substituted into formula (5), and $\mathrm{n}$ is 4 . We can get the weight of evaluation factor is:

$$
w=\left[\begin{array}{llll}
w_{1} & w_{2} & w_{3} & w_{4}
\end{array}\right]=\left(\begin{array}{llll}
0.35 & 0.306 & 0.194 & 0.15
\end{array}\right) .
$$

\subsection{Establish the membership function of evaluation factor}

As shown above, we analysis selection of evaluation and distribution of weight. Next, we need to establish the membership function of evaluation factor and the selected evaluation factor is done fuzzy process. Firstly, based on actual operating condition, we suppose the states of XLPE cable as three grades: "good, average, bad". The cable is in excellent standard when it is used in early, but the cable we monitor is used long time. So we adopt three grades that are good, average, bad; "good" expresses that the insulation state of XLPE cable is good; "average" expresses the insulation performance of XLPE cable is on the decline, which means it is in aging early time. We should intensify monitor and watch out for any abnormal condition that cable may happen; "bad" expresses the insulation performance of XLPE cable is on the decline significantly, which means it is in aging late time. When the system is warning, we should find out the failure cause after interruption maintenance or replace the cable.

$$
\mathrm{F}=\left\{f_{1}, f_{2}, f_{3}\right\}=\{\text { good, average, bad }\} .
$$

Based on Fuzzy Theory, we establish an evaluation factor set that is $U=\left\{u_{1}, u_{12}, u_{4}, u_{5}\right\}$. The $\mathrm{F}$ is served as a fuzzy set, which is $\mathrm{F}=\left\{f_{1}, f_{2}, f_{3}\right\}=\{$ good, average, bad $\}$, Among, $f_{1}, f_{2}, f_{3}$ are three fuzzy sets of evaluation cable insulation state that is based on evaluation factor set $U$. The $\mathrm{F}$ and $\mathrm{U}$ express the line and row of matrix, we can get the fuzzy relation matrix $\mathrm{M}$ that is shown in table:

Table 1 the Fuzzy Matrix M of XLPE Cable Insulation

\begin{tabular}{cccc}
\hline $\begin{array}{c}\text { Evaluation } \\
\text { factors }\end{array}$ & Good & Average & Bad \\
\hline$u_{1}$ & $a_{11}$ & $a_{12}$ & $a_{13}$ \\
$u_{12}$ & $a_{21}$ & $a_{22}$ & $a_{23}$ \\
$u_{4}$ & $a_{31}$ & $a_{32}$ & $a_{33}$ \\
$u_{5}$ & $a_{41}$ & $a_{42}$ & $a_{43}$
\end{tabular}

For calculating the membership degree of evaluation factor to insulation state, which means the value of component elements in the matrix $\mathrm{M}$, we need to establish a membership function. When the XLPE cable operates well, the evaluation factor is in normal range. It deviates from normal range when occurring insulation deterioration. So if the insulation state of cable change, its transition part is non-linear. Based on Membership Degree Assignment Method, the parameter and evaluation factor of ridge distribution membership function have correspondence, and they are clear in physical meaning. So the fuzzy sets $f_{1}, f_{2}, f_{3}$ are determined bypartial small type, medium 
type and partial big type membership function in ridge distribution. The distribution fig of three membership degree function is shown on the fig.

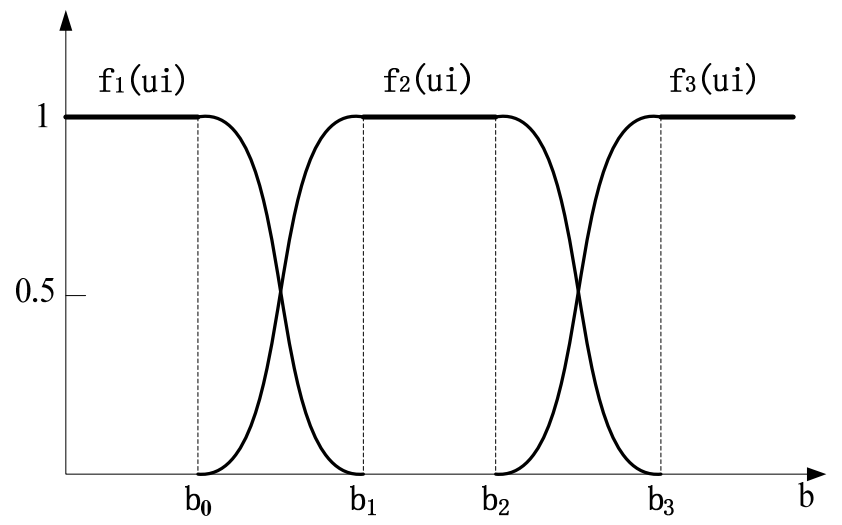

Fig 1 Distribution Fig of Membership Degree Function

As shown in fig 1, f1(ui)( partial small type), f2(ui) (medium type), f3(ui) (partial big type) express "good", "average", "bad" that are the membership function of three type insulation state. The b0-b1, b2-b3 express that the transition part of cable insulation state turn "good" into "average" and turn "average" into "bad". We can get the value of evaluation factors bi $(i=0,1,2,3)$ that is shown in the table after referringto preventive test and past criterion of insulation.

Table 2 the Value of Evaluation Factors bi $(i=0,1,2,3)$

\begin{tabular}{ccccc}
\hline $\begin{array}{c}\text { Evaluation } \\
\text { factors }\end{array}$ & $\mathrm{b}_{0}$ & $\mathrm{~b}_{1}$ & $\mathrm{~b}_{2}$ & $\mathrm{~b}_{4}$ \\
\hline$u_{1}(\mathrm{~mA})$ & 20 & 100 & 200 & 300 \\
$u_{12}$ & 0.2 & 0.3 & 0.6 & 0.7 \\
$u_{4}\left({ }^{\circ} \mathrm{C}\right)$ & 30 & 40 & 45 & 50 \\
$u_{5}(\%)$ & 65 & 85 & 90 & 95 \\
\hline
\end{tabular}

After determining the boundary value of evaluation factor, we solve the membership degree of evaluation factors to insulation states, which is the value of component elements in the matrix M:

$$
\mathrm{A}_{i}=\left\{\begin{array}{cc}
1 & \mathrm{C}_{i} \leq \mathrm{C}_{\min } \\
1-\left(\mathrm{C}_{i}-\mathrm{C}_{\min }\right) /\left(\mathrm{C}_{\max }-\mathrm{C}_{\min }\right) \mathrm{C}_{\min }<\mathrm{C}_{i} \leq \mathrm{C}_{\max } \\
0 & \mathrm{C}_{i}>\mathrm{C}_{\max }
\end{array}\right.
$$

In the formal, the $\mathrm{A}$ is the number $\mathrm{i}$ membership degree of evaluation factor; $\mathrm{Ci}$ is the measured value of evaluation factor; Cmax are Cmin are the boundary limited value.

When integrated pulse frequency $u_{12}$ of the current of peak pulse is done Fuzzy processing, we need to consider a problem: different value of the current of peak pulse will produce different pulse frequency, and in different peak value, the pulse frequency is identical but the insulation state must be different. So when integrated pulse frequency of the current of peak pulse is done Fuzzy processing, we should consider the value of the current of peak pulse and the pulse frequency at the same time. Synthesizing the characteristics of above, the integrated pulse frequency of the current of peak pulse is done Fuzzy processing by following way for reflecting insulation state of electrical cable. To different current of peak pulse, different fuzzy values are defined by occurrence number that is counted in set time. Finally, the fuzzy membership degree is determined by fuzzy operation. 


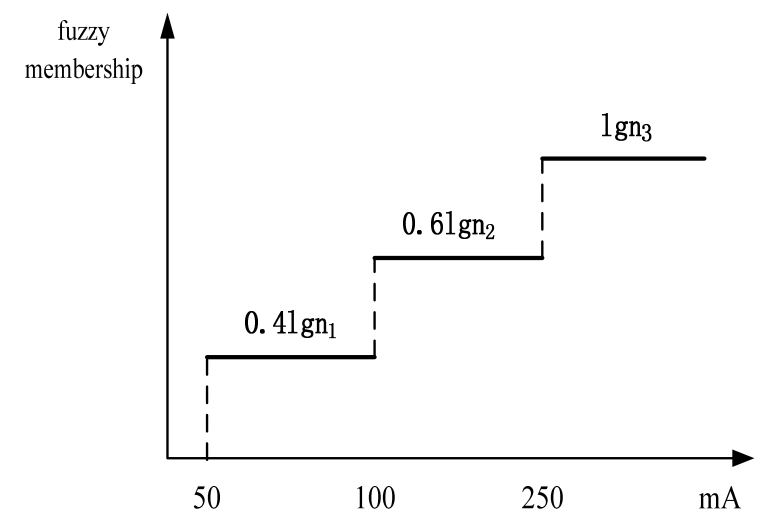

Fig 2 the Distribution fig of the integrated pulse frequency of the current of peak pulse's value

The current of peak pulse is classified into three standards that are 50 100,100 250 and $250 \sim$ $\infty$; The fuzzy value is $0.4 \operatorname{lgn} 1$ in $50 \sim 100$ range; The fuzzy value is $0.6 \operatorname{lgn} 1$ in $100 \sim 250$ range; The fuzzy value is $\operatorname{lgn} 3$ in $250 \sim \infty$ range. Among, n1, n2, n3 are the occurred times of current of peak pulse in a minute in $50 \sim 100,100 \sim 250$ and $250 \sim \infty$ range. Among, $u_{12}$ $=\max \left\{0.4 \operatorname{lgn}_{1}, 0.6 \operatorname{lgn}_{2}, \operatorname{lgn}_{3}\right\}$, we can get the membership degree of integrated pulse frequency of the current of peak pulse.

\subsection{The method of fuzzy integrated evaluation}

The insulation state of XLPE cable is evaluated by the method of fuzzy integrated evaluation that is based on fuzzy relation formula $\mathrm{Y}=\mathrm{W} \circ \mathrm{R}$, and $\circ$ is fuzzy operator. We choose the fuzzy operator of weighted averaging. The relation formula is:

$$
\mathbf{y}_{\mathfrak{i}}=\sum_{\mathfrak{i}=1}^{\mathbf{n}} \mathbf{w}_{\mathfrak{i}} \mathbf{r}_{\mathfrak{i j}}
$$

In the formula (8), the Y expresses the assessment result of final insulation state of XLPE cable, the $\mathrm{W}$ expresses the weight of evaluation factors, the $\mathrm{R}$ expresses component value in fuzzy matrix M.

\section{Structure the on-line monitor warning device}

The on-line monitor warning device of XLPE cable is constructed by two large parts that are field ends and back monitoring server. The field ends is responsible for real-time sampling data of cable insulation parameter, processing and packing data, transporting data. The task of back monitoring sever is providing a on-site monitoring platform for engineer. The structure diagram of whole device is shown on Fig 3.

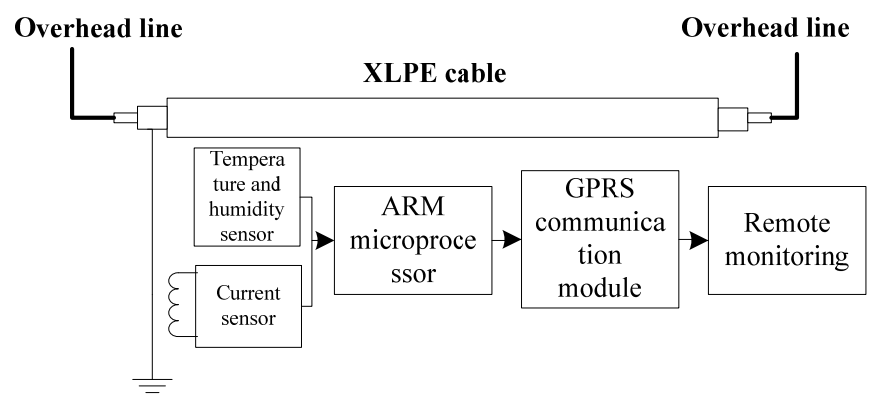

Fig 3 the structured flowchart of on-line monitoring device

\subsection{Design the frame of on-line monitor warning device}

When design the on-line monitoring warning device of electrical cable that is used in city network for on-line monitoring grounding line current, pulse current, cable joint surface temperature, 
environmental relative humidity and so on, the data that is used to detect and process is done by fuzzy theory algorithms. It is used to assess insulation state for detecting and judging easily the condition whether the electrical cable occurs to insulation aging, even breakdown or not.

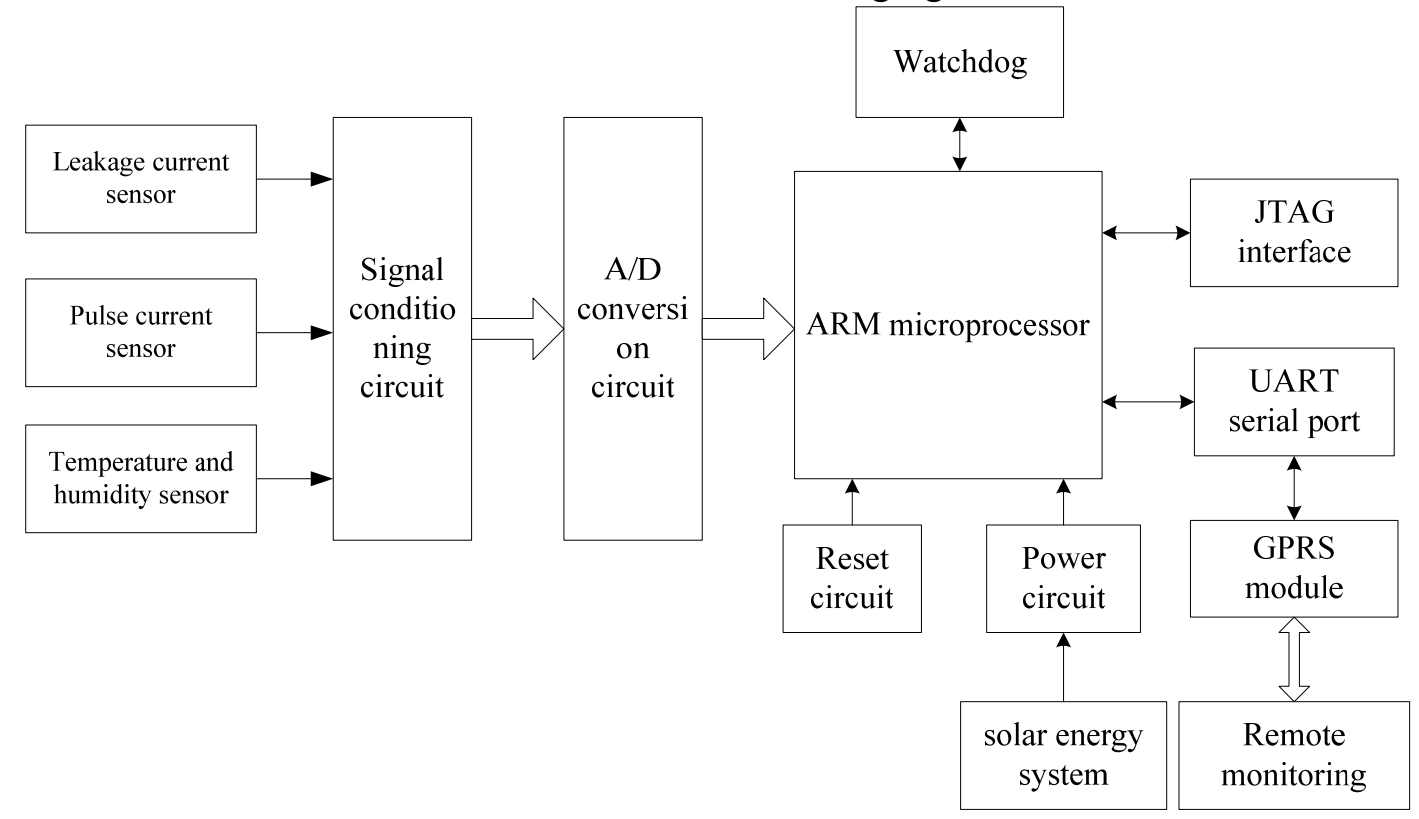

Fig 4 the hardware flowchart of on-line monitoring device

As shown on fig 4 that is the hardware flowchart of on-line monitoring device, it is consist of two current sensors, environmental temperature and humidity sensor, signal conditioning circuit, A/D converting circuit, ARM microprocessor, GPRS module remote communication circuit, solarpower supplying circuit and background monitoring platform.According the leakage current signal, temperature signal and humidity signal of electrical cable that is measured by two current sensors and the environmental temperature and humidity sensor that is mounted in the near grounding wire of cable, the on-line monitoring pre-warning device takes the signal into signal conditioning circuit. After being done filtering and quantizing, the signal is processed by ARM microprocessor monitoring unit in the field. Finally, it is transported to the background monitoring platformthrough GPRS module remote communication circuit. Based on the fuzzy theory algorithms, we assess data to electrical cable insulation state. By Statistical analysis and judgement comparing, we can know the final insulation state level of electrical cable and the solution whether need to warn or not.

\subsection{Structure the main hardware of on-line monitoring device}

1) Select the chip of on-line monitoring warning device

The device that is in the field is a processing unit whose core is STM32F103 microprocessor of ARM framework, which of processor is a High-performance, low power, low-cost 32-bit cpu whose maximum frequency is $72 \mathrm{MHz}$ and embedding $32 \mathrm{~K}$ to $128 \mathrm{~Kb}$ flash.

2) Design theleakage current sensor

The current that is measured by leakage current sensor is small and both at $\mathrm{mA}$ level and it operates in the field that is disturbed seriously by electromagnetism. So we design a zero flux through small current sensor. We choose the permeability alloy whose loss is small and initial permeability is high as iron core material. We use deep negative feedback techniques and unique shielding measures. And we take the automatic compensation to iron core for operating in ideal zero flux state.

3) Design Pulse current sensor

The partial discharge pulse duration of XLPE cable insulation is on a nanosecond time scale, which of rise time is extremely short and the power of signal is dispersed with broadband ranging from dozens $\mathrm{kHz}$ to several GHz. So, we design a current sensor of broadband Rogowski Coil type, which is based on electromagnetic coupling principle and is consist of magnetic core, coils, integral resistors and metallic enclosure. For getting the signal that is proportional with $\mathrm{i}(\mathrm{t})$ directly, the 
measuring system must be insert by an integral resistance. The equivalent circuit is shown on the fig 5 , among $R_{s}$ expresses equivalent resistance of coil, $C_{s}$ expresses equivalent stray capacitance of coil, $R$ expresses integral resistors of circuit which form the integral circuit with $L_{s}, u(t)$ expresses mutual induced EMF, $\mathrm{u}_{\mathrm{o}}(\mathrm{t})$ the voltage of integral resistance, $\mathrm{i}(\mathrm{t})$ expresses induced current of coil.

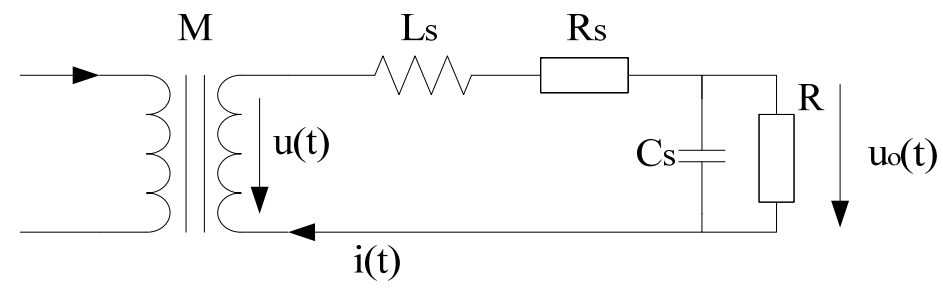

Fig5 Equivalent circuit diagram of Rogowski Coil

According to equivalent circuit, we can get the equation of circuit that is:

$$
\mathrm{u}_{\mathrm{o}}(\mathrm{t})=\mathrm{M} \frac{\mathrm{R}}{\mathrm{L}_{\mathrm{s}}} \mathrm{i}(\mathrm{t})
$$

As is seen, the output voltage is directly proportional to measured current after ignoring stray capacitance. The method that is accomplished linear output by using parameter of coil structure is called as Self integral method whose tenable condition is $\omega \mathrm{L}_{s}=\mathrm{R}_{\mathrm{s}}+\mathrm{R}$. According to the references, transmission function of Rogowski Coil is similar to High frequency small signal parallel resonance circuit. According to the high frequency small-signal theory, the transmission bands of Rogowski Coil is:

Upper frequency band:

$$
\mathrm{f}_{\mathrm{H}}=\frac{1}{2 \pi} \frac{\mathrm{L}_{\mathrm{s}}+\mathrm{RR}_{\mathrm{S}} \mathrm{C}_{\mathrm{s}}}{\mathrm{L}_{\mathrm{s}} \mathrm{RC}_{\mathrm{s}}} \approx \frac{1}{2 \pi} \frac{1}{\mathrm{RC}_{\mathrm{s}}}
$$

Lower frequency band:

$$
\mathrm{f}_{\mathrm{L}}=\frac{1}{2 \pi} \frac{\mathrm{R}+\mathrm{R}_{\mathrm{s}}}{\mathrm{L}_{\mathrm{s}}+\mathrm{RR}_{\mathrm{s}} \mathrm{C}_{\mathrm{s}}} \approx \frac{1}{2 \pi} \frac{\mathrm{R}+\mathrm{R}_{\mathrm{s}}}{\mathrm{L}_{\mathrm{s}}}
$$

For making the running frequency band become wider, the $f_{H}$ should be larger and the $f_{L}$ should be smaller. So we choose an optimal integral resistance that combine with turn number of coil for making the current sensor run in suitable frequencyand ensuring the demand of response sensitivity.

\section{Software build of the online monitoring and warning structure}

Softwaresystem includes the design of the field monitoring platform software and the background software. field platform includes: various data identification and accessof Power cable leakage current ,temperature and humidity, GPRS remote communications, online software upgrades, low power consumption of hardware design and so on; while , the background monitoring software is mainly to design a remote real-time monitoring software background and fuzzy algorithm insulation condition assessment warning software, which can provide staff with a visual monitoring the state of the power cable insulation remote interface and have a fault early warning functionto improve the work efficiency. 


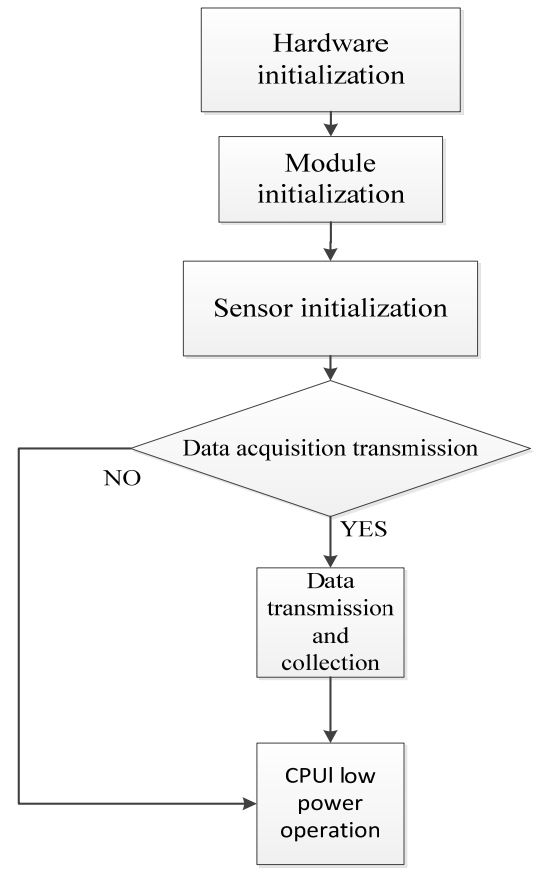

Fig 6 Main process diagram of the system

Main process diagram of the system is shown in fig6, the program initialization plays an important role of stable operation of the whole system, including hardware initialization (register configuration,a/d converter, timer and port), initialization module(GPRS module), sensor initialization.In the process of data collection and sending, the ADC enabled, the DMA enabled, then the collected data conversion and packaging, then sending to the background monitoring platform through the GPRS module;during the time system is out of work, the whole device enter a dormant state, to run the low power consumption, prolong the use time of battery. considering the embedded system in the actual operation process, system may be flawed, new functions needed or user requirements, the system needs maintain and update, therefore, the system online upgrade functionincreased, and download upgrades when plant dormancy.

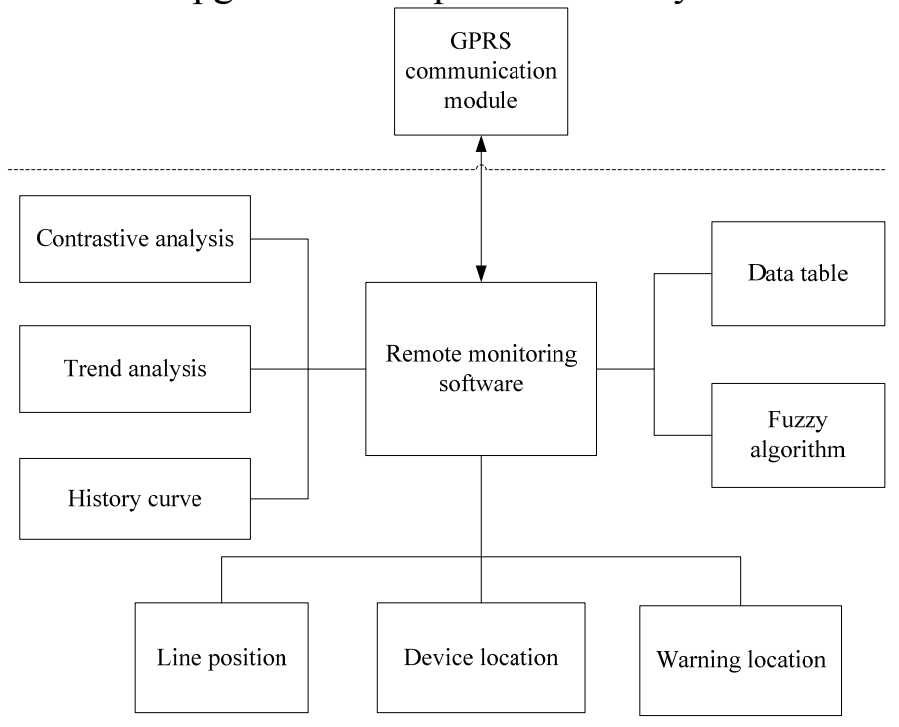

Fig 7 Background monitoring software structure

In fig 7, for visual display describedproperties cable size of all the electric parameters, the background monitoring software establish a database, including data storage, query, delete, export, and printing, , visual display cable electric parameter changes over timeby way of the chart.In addition, the location of the various on-line monitoring device in the city are shown on the map, to 
facilitate the background monitoring to observe the running state of cable in each segment, in the event of early warning, we can immediately know the specific cable line position.

\section{Field Experiment Analysis}

To verify the validity of the method and device, cable insulation on-line condition monitoring and evaluation have been done for $10 \mathrm{kV}$ XLPE cable.The cable line is 110 metres long, respectively by three sensors to collect leakage current effective value, peak value of pulse current, pulse current frequency, cable joint surface temperature, and environment relative humidity. Collected parameter values are shown in table 3

Table 3 cable parameters measured values

\begin{tabular}{cccccc}
\hline $\begin{array}{c}\text { Related } \\
\text { parameters }\end{array}$ & $\mathrm{Fi}(\mathrm{mA})$ & $\mathrm{Fp}(\mathrm{mA})$ & $\mathrm{Ff}($ times $)$ & $\mathrm{T}\left({ }^{\circ} \mathrm{C}\right)$ & $\mathrm{H}(\%)$ \\
\hline $\begin{array}{c}\text { Value of } \\
\text { online } \\
\text { monitoring }\end{array}$ & 27.5 & 35 & 2 & 32.1 & 76.09 \\
\hline
\end{tabular}

According Numerical coefficients in the on-line monitoring, taken into formula (7), and each evaluation factor for membership degree of the insulation state, the $M$ value of each component element in the fuzzy matrix.The fuzzy matrix $M$ are shown in table 4 below:

Table 4 The fuzzy matrix $M$

\begin{tabular}{cccc}
\hline $\begin{array}{c}\text { Evaluation } \\
\text { factors }\end{array}$ & excellent & good & bad \\
\hline$u_{1}(\mathrm{~mA})$ & 0.906 & 0.094 & 0 \\
$u_{12}$ & 1 & 0 & 0 \\
$u_{4}\left({ }^{\circ} \mathrm{C}\right)$ & 0.79 & 0.21 & 0 \\
$u_{5}(\%)$ & 0.445 & 0.555 & 0
\end{tabular}

Each component in the fuzzy matrix $\mathrm{M}$ value and cable weight value of each evaluation factor are taken into formula (8), respectively, the final cable insulation evaluation results.Evaluation result is shown in table 5 :

Table 5 final results of cable insulation state

\begin{tabular}{cc}
\hline Insulation state & Final results \\
\hline Good & 0.8431 \\
Average & 0.1569 \\
bad & 0
\end{tabular}

Using the fuzzy theoryto evaluate the insulation condition of the XLPE cable.from the above chart, it can be seen that able insulation state is "good" for 0.8431 the outcome, "average" for 0.1569 , "bad" for 0 . The evaluation results accord with the actual running conditionof a $10 \mathrm{kv}$ cable insulation in Zhejiang province, no insulation fault ofthe cable line has occurred in operation of two years.

\section{Conclusion}

Given that XLPE cable insulation single online monitoring methods cannot judge the state of the cable insulation very well, the method and the device of insulation condition assessment based on fuzzy theory were developed, by field deviceof a good anti-jamming and the data acquisition and 
multi-function background monitoring software, which can real-time monitorcable running status and ensure that the cable fault timely warning.Field operation shows that the device is running in good condition, have a fast computing speed, short response time and sending cable insulation parameters in an effective way; Background monitoring platform is of simple operation and receiving data with high efficiency, human interface design, the fault accurately and timely warning. With the continuous development of online monitoring technology, constantly enrich XLPE cable insulation monitoring parameters, based on the theory of fuzzy evaluation methods, there is no doubt that it will be an effective XLPE cable insulation condition assessment methodusing all kinds of insulation parameters.

\section{References}

[1] Li Honglei, Zhang Li, Li Lihua. Online monitoringand detection techniques of XLPE cables[J].Electric Power, 2010, 43(12):31-34.

[2] Xu Hongyi, Huang Bin, Guo Heqing. Summary and Design of On-line Monitoring Method for XLPE High-voltage Cable[J]. Hubei Electric Power ， 2009 , 33(6):38-39, 76.

[3] Zhu Xiaohui, Du Boxue, Zhou Fengzheng, et al.Progress of On-line Monitoring and Detecting Technique for High Voltage XLPE Cable[J]. Insulating Materials, 2009, 42(9):58-63.

[4] Dong Xiaobing, Cai Jun, Jiang Xiuchen, et al.On-line monitoring for $10 \sim 35 \mathrm{kV}$ XLPE Cable[J].Electric Power Automation Equipment , 2005 , 25(9):20-24.

[5] Hu Guanlin, Li Juan. Application of D-S evidence theory in fault diagnosis[J]. Computer and Digital Engineering, 2007, 35(8) :151-153.

[6] Wang Hongxin, Cheng shukang, Wen Xishan, et al. AC insulation characteristics of XLPE in the course of aging[J].High Voltage Engineering, 2005, 31(3):7-9.

[7] Luo Huayu, Guan Genzhi, Yi Xiaoyu. Study of on-line monitoring of XLPE cable by earth line current method[J].High Voltage Engineering, 2005, 31(11):63-65.

[8] Xie Jijian, Liu Cheng-ping. Fuzzy mathematics method and its application[M]. Wuhan , China: Huazhong University of Science and Technology Press, 2006.

[9] Zhuo Jinyu. Design principle of power cable[M].Beijing, China: China Machine Press, 1999.

[10]Wu Guangning. Theory and practice of electrical equipment state monitoring[M]. Beijing, China: Tsinghua University Press, 2005.

[11]Chen Ruilong. The design of partial discharge on-line monitoring system for XLPE power cable[D]:[ Master Degree Thesis].Shanghai:Shanghai jiao tong university,2014 